\title{
Clinical, CSF, and MRI findings in Devic's neuromyelitis optica
}

\author{
J I O'Riordan, H L Gallagher, A J Thompson, R S Howard, D P E Kingsley, \\ E J Thompson, W I McDonald, D H Miller
}

\begin{abstract}
Objectives-Since Devic's original description of neuromyelitis optica in 1894 there has been much debate regarding its aetiology. A specific cause has been identified in a minority of cases but in most the question has arisen whether or not Devic's neuromyelitis optica is a variant of multiple sclerosis. This study was undertaken to help clarify this issue.

Methods-Neuromyelitis optica was defined as (1) a severe transverse myelitis; (2) an acute unilateral or bilateral optic neuropathy; (3) no clinical involvement beyond the spinal cord or optic nerves, and (4) a monophasic or multiphasic illness. The clinical and autoantibody status was documented. Patients underwent CSF examination and MRI of brain and spinal cord.
\end{abstract}

Results-Twelve patients, with a mean age of presentation of 35.1 years, were seen. Eleven were women; vision was reduced to counting fingers or worse in 10 patients and seven became confined to a wheelchair. Examination of CSF showed local synthesis of oligoclonal bands in only two patients and a neutrophil pleocytosis in two. A possible aetiology was identified in five: a specific connective tissue disorder (two), pulmonary tuberculosis (one), and possible acute disseminated encephalomyelitis (two). Six had non-specific increases in various autoantibodies. Eleven patients underwent MRI of the brain and spinal cord. In 10 there were diffuse abnormalities involving cervical and thoracic cords with extensive swelling in the acute phase. Brain MRI was normal in five; in five there were multiple deep white matter lesions, and one patient had minor age related changes.

Conclusion-It is proposed that Devic's neuromyelitis optica is a distinctive disorder with some clinical, CSF, and MRI features different from those found in classic multiple sclerosis. In most cases a specific aetiology is not identified, but an immunological mechanism of tissue damage seems likely.

\section{$(尹$ Neurol Neurosurg Psychiatry 1996;60:382-387)}

Keywords: neuromyelitis optica; multiple sclerosis

Sir Christopher Allbutt first alluded to an association between spinal cord disease and visual loss in $1870 .{ }^{1}$ Eugene Devic, a physician at L'Hopital de la Croix-Rousse in Lyon, subsequently described a case and inspired his student Fernand Gault to write a thesis on the topic. ${ }^{2-4}$ It was Gault who suggested a separate clinical entity termed neuroptico-myelites (neuromyelitis optica). The syndrome soon became known by Devic's name and is characterised by a severe acute transverse myelitis plus an acute or subacute optic neuropathy with or without recovery. It may follow a monophasic or multiphasic pattern. Despite the many extensive reviews over the past century its status as a distinct entity has been uncertain..$^{5-8}$ In a proportion of cases a specific cause has been identified, ${ }^{9-18}$ and in most cases of uncertain cause there has been much debate as to whether it is a variant of multiple sclerosis or a distinct clinical syndrome. We report the clinical, CSF, and MRI findings of 12 patients with Devic's neuromyelitis optica and discuss their importance.

\section{Materials and methods}

The case records of patients attending the National Hospital of Neurology and Neurosurgery, Queen Square and Moorfield's Eye Hospital between 1986 and 1994 with neuromyelitis optica were reviewed. The disease was defined as (1) a complete transverse myelitis (an acutely developing and severe paraparesis or tetraparesis affecting motor and sensory pathways with or without sphincteric involvement; evolving over one to 14 days, with a sensory level, and in the absence of cord compression); (2) an acute unilateral or bilateral optic neuropathy; (3) no clinical involvement beyond the spinal cord or optic nerves; and (4) the illness could be monophasic or multiphasic. The clinical course of each patient was documented, and the eventual outcome was graded as mild-minimal weakness and fully ambulatory; moderate-moderate weakness although still ambulatory with the aid of unilateral or bilateral assistance; or severe-severe paraparesis, confined to wheelchair or bed.

In addition to the standard haematological investigations all patients had an autoantibody screen consisting of antinuclear antibody, rheumatoid factor, anti- double stranded DNA, thyroid thyroglobulin, thyroid microsomal, gastric parietal, smooth muscle, mitochondrial, reticulin, and antiphospholipid antibodies.

The CSF was analysed as follows : a qualita- 
tive analysis involving electrophoresis on acrylamide gel, light chain immunoblots of acrylamide gel, and IgG immunoblots of isoelectric focusing to identify the presence of serum proteins, evidence of blood-brain barrier breakdown and the presence of oligoclonal banding; a quantitative analysis of total protein and components using a densitometer scan of acrylamide gel and total white cell count, white cell differential, and cytology.

Magnetic resonance imaging was performed on a Picker $0.5 \mathrm{~T}$ or a GE Signa $1.5 \mathrm{~T}$ scanner. Brain MRI was performed in the axial plane with $5 \mathrm{~mm}$ thick slices using $\mathrm{T} 1$ and $\mathrm{T} 2$ weighted sequences. In addition three patients received intravenous gadolinium DPTA. The brain was divided into seven areas : frontal, temporal, parietal, occipital, basal ganglia, brain stem, and cerebellum. Lesion size was graded as 1: $<5 \mathrm{~mm}, 2: 5-10 \mathrm{~mm}$, 3: $>10 \mathrm{~mm}$ or 4 : confluent. The spinal cord was imaged in the sagittal plane with axial images through areas of abnormality. The spinal cord was assessed with regard to cord swelling, cord atrophy, canal size, and signal intensity.

\section{Results}

Twelve patients fulfilled the diagnostic criteria for entry to the study. Four patients were of Asian origin, one African, one Afro-West Indian, five Caucasian, and one Mediterranean. There were 11 women and one man with a mean age of 40 (range 16-65) years. A possible aetiology was identified in five cases; two patients ( 10 and 12) developed a monophasic transverse myelitis and bilateral optic neuritis several weeks after a non-specific infective illness, and the probable diagnosis was acute disseminated encephalomyelitis. Another, with a history of pulmonary tuberculosis five years previously but with no clinical, radiological, or laboratory evidence of recurrence, developed bilateral optic neuropathy followed by transverse myelopathy after a period of six months without further episodes. All other patients had multiphasic involvement of the optic nerve or spinal cord. Two patients had a coexisting collagen vascular disease (systemic lupus erythematosus and mixed connective tissue disease). These two and six others had raised concentrations of various autoantibodies. The interval between development of

Table 1 CSF findings

\begin{tabular}{rlllcl}
\hline & $\begin{array}{l}\text { Blood-brain } \\
\text { barrier }\end{array}$ & $\begin{array}{l}\text { Local synthesis } \\
\text { oligoclonal } \\
\text { bands }\end{array}$ & $\begin{array}{l}\text { Total } \\
\text { protein } \\
\text { (mg/dl) }\end{array}$ & $\begin{array}{l}\text { White } \\
\text { cell } \\
\text { count/mm }\end{array}$ & $\begin{array}{l}\% \\
\text { Polymorphs }\end{array}$ \\
\hline 1 & breakdown & + & 75 & 1 & 0 \\
2 & + & - & 140 & 4 & 94 \\
3 & + & - & 67 & 18 & NA \\
4 & + & - & NA & NA & NA \\
5 & NA & - & 38 & 1 & 14 \\
6 & + & - & 280 & 58 & 18 \\
7 & + & - & 52 & 1 & 14 \\
8 & + & + & 140 & 5 & NA \\
9 & + & + & 208 & 38 & 0 \\
10 & + & - & 147 & 225 & 80 \\
11 & + & - & 110 & 110 & NA \\
12 & + & - & & &
\end{tabular}

NA = not available. myelopathy and optic neuropathy was less than two years in 10 patients. In one there was an interval of five years.

\section{MYELOPATHY}

The mean age of onset of myelopathy was $35 \cdot 1$ (range 16-60) years. Four patients had a single episode with poor recovery. Four patients had a single relapse; this followed a period of one year in one, two years in two, and 14 years in another. Four patients had more than one relapse. The myelopathy involved the cervical cord clinically in 10 patients and response to treatment was variable but generally poor. All patients received a course of high dose intravenous methyl prednisolone and three received cyclophosphamide. Two patients exhibited steroid dependency with worsening of both myelopathy and optic neuropathy on reduction of the steroid dosage. Another had an episode of profound bradycardia during methyl prednisolone infusion. Three patients required prolonged intensive care with mechanical ventilation, one necessitating a tracheostomy, during the acute stages. Four patients made a good initial recovery but developed persistent paraparesis after subsequent relapses. At follow up five patients were ambulatory with the aid of unilateral or bilateral assistance; seven were confined to a wheelchair.

OPTIC NEUROPATHY

The mean age of onset of optic neuropathy was $35 \cdot 2$ (range 14-61) years. This was bilateral in 10 patients and followed a relapsingremitting pattern in five. The prognosis for visual symptoms was generally poor. Ten patients had persistently diminished vision to counting fingers or worse in one or both eyes. Of these, visual evoked responses were absent in nine. In one patient there was a normal latency but diminished amplitude; a pattern more suggestive of axonal damage than demyelination. Visual evoked responses were not available for one patient. Patient 11 underwent open biopsy of the right optic nerve near the chiasm, which showed reactive astrocytosis.

CSF

All patients had one or more CSF examinations. In 10 there was negative oligoclonal banding. Of those who were positive, there was a diffuse increase in $\gamma$ globulins with identical oligoclonal banding in both CSF and serum in two indicating systemic synthesis of IgG. Thus only two patients showed intrathecal synthesis of oligoclonal bands. Patient 9 had serial CSF which showed local synthesis of IgG in the first sample plus a restricted antibody response to an antigen outside the CNS in subsequent samples. The total protein count was raised in nine. Seven patients had five or more white cells per $\mathrm{mm}^{3}$; differential white cell count showed a predominantly polymorphic leucocytosis in two; in three others there was an abnormal presence of polymorphs; one patient had atypical or reactive lymphocytes on cytology. 
Table 2 Clinical and laboratory findings

\begin{tabular}{|c|c|c|c|c|c|c|c|c|c|c|}
\hline \multirow[b]{2}{*}{ Patient no } & \multirow[b]{2}{*}{ Sex } & \multicolumn{2}{|c|}{ Age at presentation } & \multirow[b]{2}{*}{ Autoantibody } & \multirow{2}{*}{$\begin{array}{l}\text { Possible } \\
\text { specific } \\
\text { causes }\end{array}$} & \multicolumn{2}{|c|}{ Brain MRI } & \multicolumn{2}{|c|}{ Spinal Cord MRI } & \multirow[b]{2}{*}{$\begin{array}{l}\text { Pattern of } \\
\text { illness }\end{array}$} \\
\hline & & Myelopathy & $\begin{array}{l}\text { Optic } \\
\text { neuropathy }\end{array}$ & & & Baseline & Follow up & $\begin{array}{l}\text { No abnormal } \\
\text { segments }\end{array}$ & Swelling & \\
\hline 1 & $\mathbf{F}$ & 53 & 48 & $\begin{array}{l}\text { Thyroid thyroglobulin } \\
\text { Thyroid microsomal }\end{array}$ & & ND & ND & ND & ND & Multiphasic \\
\hline $\begin{array}{l}2 \\
3\end{array}$ & $\begin{array}{l}\mathbf{F} \\
\mathbf{F}\end{array}$ & $\begin{array}{l}33 \\
35\end{array}$ & $\begin{array}{l}32 \\
37\end{array}$ & $\begin{array}{l}\text { Thyroid thyroglobulin } \\
\text { Thyroid microsomal }\end{array}$ & Tuberculosis & - & - & $\begin{array}{l}\text { C7 to T6 } \\
\text { C3 to T9 }\end{array}$ & $\begin{array}{l}+ \\
+\end{array}$ & $\begin{array}{l}\text { Monophasic } \\
\text { Multiphasic }\end{array}$ \\
\hline $\begin{array}{l}4 \\
5\end{array}$ & $\begin{array}{l}M \\
F\end{array}$ & $\begin{array}{l}19 \\
42\end{array}$ & $\begin{array}{l}19 \\
41\end{array}$ & $\begin{array}{l}\text { ANA, smooth muscle } \\
\text { DS DNA, } \\
\text { Gastroparietal } \\
\text { Acetyl choline rec ab } \\
\text { Low C3 \& C4 }\end{array}$ & SLE & - & - & $\mathrm{C} 5$ to $\mathrm{T} 11$ & + & Multiphasic \\
\hline 6 & $\mathbf{F}$ & 21 & 22 & Thyroid thyroglobulin & & + & ND & $\begin{array}{c}\mathrm{C} 1 / 2 \text { and } \\
\mathrm{T} 1 / 2\end{array}$ & - & Multiphasic \\
\hline $\begin{array}{l}7 \\
8\end{array}$ & $\begin{array}{l}F \\
F\end{array}$ & $\begin{array}{l}18 \\
56\end{array}$ & $\begin{array}{l}17 \\
58\end{array}$ & $\begin{array}{l}\text { ANA } \\
\text { Smooth muscle } \\
\text { Rh factor }\end{array}$ & & $\begin{array}{l}+ \\
+\end{array}$ & $\begin{array}{l}\text { ND } \\
\text { ND }\end{array}$ & $\begin{array}{l}\text { C2 to T5 } \\
\text { C3 to } \mathrm{C} 7\end{array}$ & $\begin{array}{l}+ \\
+\end{array}$ & $\begin{array}{l}\text { Multiphasic } \\
\text { Multiphasic }\end{array}$ \\
\hline 9 & $\mathbf{F}$ & 60 & 61 & $\begin{array}{l}\text { ANA, Low C3 } \\
\text { Thyroid thyroglobulin } \\
\text { Gastroparietal }\end{array}$ & MCTD & + & No change & $\mathrm{C} 1$ to $\mathrm{T} 10$ & + & Multiphasic \\
\hline 10 & $\mathbf{F}$ & 36 & 36 & Gastroparietal & $\begin{array}{l}\text { Probable } \\
\text { ADEM }\end{array}$ & + & $\begin{array}{l}\text { Partial } \\
\quad \text { resolution }\end{array}$ & $\begin{array}{l}\text { Medulla to } \\
\text { C7 }\end{array}$ & + & Monophasic \\
\hline $\begin{array}{l}11 \\
12\end{array}$ & $\begin{array}{l}F \\
F\end{array}$ & $\begin{array}{l}16 \\
32\end{array}$ & $\begin{array}{l}14 \\
32\end{array}$ & $\begin{array}{l}\text { Nil } \\
\text { Nil }\end{array}$ & $\begin{array}{c}\text { Probable } \\
\text { ADEM }\end{array}$ & $\overline{+}$ & $\begin{array}{l}\overline{\text { Partial }} \\
\quad \text { resolution }\end{array}$ & $\begin{array}{l}\mathrm{C} 3 \text { to } \mathrm{T} 5 \\
\text { Extensive }\end{array}$ & $\begin{array}{l}+ \\
+\end{array}$ & $\begin{array}{l}\text { Multiphasic } \\
\text { Monophasic }\end{array}$ \\
\hline
\end{tabular}

ND = not done; ANA = anti nuclear antibody; DS DNA = double stranded DNA; acetylcholine rec ab = antiacetylcholine receptor antibody; SLE = systemic lupus erythematosus; $M C T D=$ mixed connective tissue disease; $A D E M=$ acute disseminated encephalomyelitis.

Figure 1 Sagittal T2 weighted MRI of spinal cord of patient 5 showing extensive swelling of the cervical and thoracic segments with high signal intensity.

\section{BRAIN MRI}

Eleven patients underwent MRI of both brain and spinal cord. Four patients had serial brain and six serial spinal cord imaging. The interval between scans varied between two months and four years. the brain parenchyma was entirely normal in five. In a sixth patient aged 60 there



was a confluent periventricular lesion and a single separate lesion of less than $5 \mathrm{~mm}$. This was unchanged over three years and considered to be a normal age related finding. Three patients had normal serial brain imaging. Five patients exhibited multiple cerebral white matter abnormalities considered to be abnormal 
Figure 2 T2 weighted axial MRI of brain of patient 10 showing multiple deep white matter lesions.

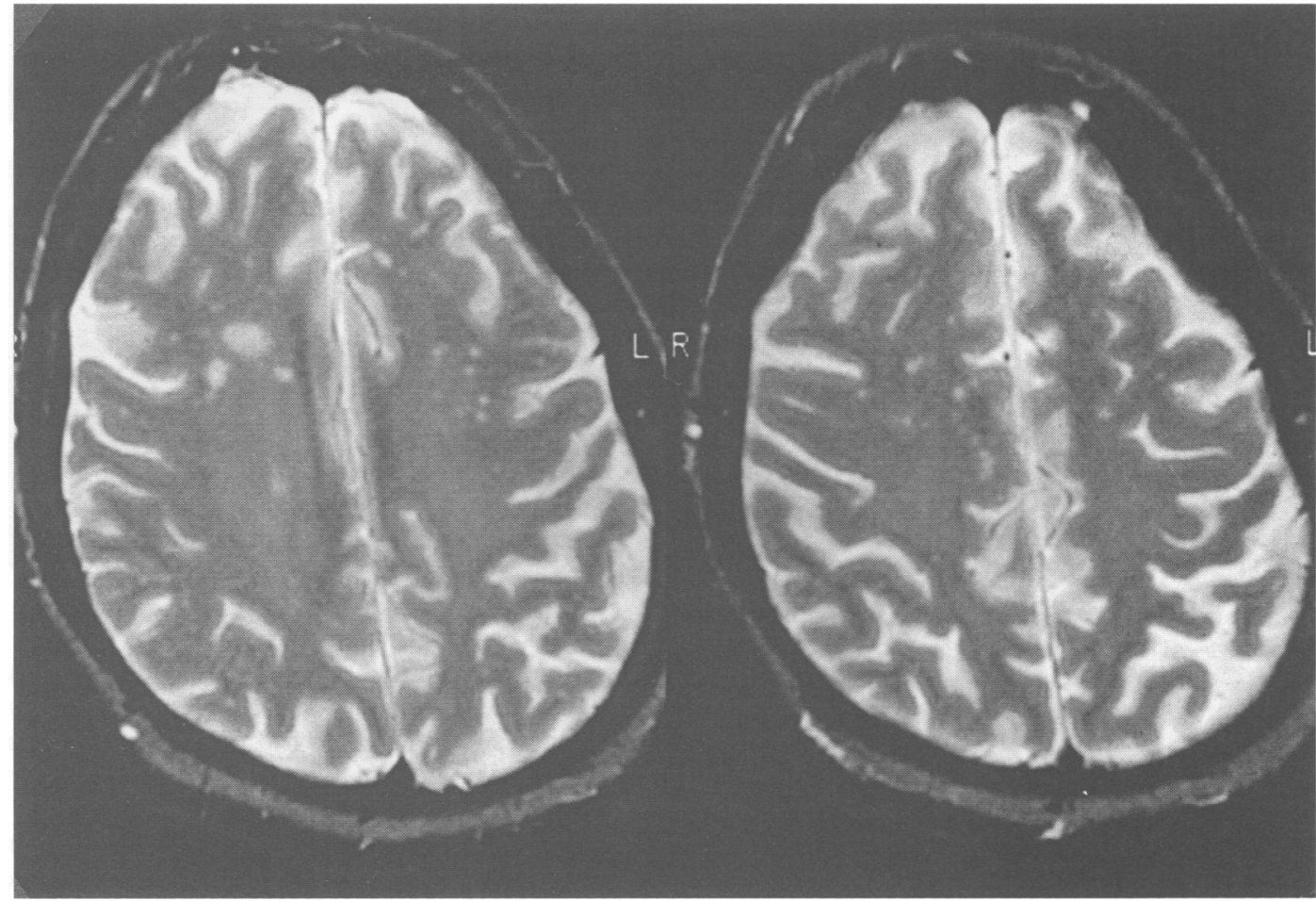

for their age. On follow up, there was partial reduction in the abnormalities in the two patients with possible acute disseminated encephalomyelitis. Abnormalities tended to be supratentorial and located predominantly in the frontoparietal white matter. There was a single lesion in the basal ganglia. Two patients had signal change in the optic nerves; one with associated swelling. Apart from involvement of the lower medulla in continuity with the cervical cord abnormalities infratentorial lesions were not seen.

SPINAL CORD MRI

Ten patients had spinal cord swelling which was usually extensive during acute episodes of myelitis. Their length varied from a single level only to diffuse involvement of both cervical and thoracic cords; usually multiple levels were involved by the symptomatic lesion. There was an associated high signal intensity on the T2 weighted sequence. After the acute phase, swelling usually diminished and signal change became less intense, but in two patients there was some persistence of swelling and signal change for up to 18 months. One patient did not show cord swelling during the acute phase, but there were signal hyperintensities at the $\mathrm{C} 1 / 2$ and $T 1 / 2$ levels. Diffuse enhancement over two segments of the spinal cord in one and seven in another was seen after intravenous gadolinium DPTA.

\section{CASE ILLUSTRATIONS}

\section{Patient 5}

A 41 year old Caucasian woman with a previous history of myasthenia gravis developed complete loss of vision in the left eye over five days without recovery. Four months later she had a complete transverse myelitis with sensory level to T4 and a generalised livido reticularis rash. She had an erythrocyte sedimentation rate of 60 ; low $\mathrm{C} 3$ and $\mathrm{C} 4$ concen- trations; and a positive DNA binding antibody compatible with a diagnosis of systemic lupus erythematosus. The myelopathy improved after treatment with steroids and cyclophosphamide. Two years later there was recurrence of myelitis with partial response to treatment. Brain MRI and CSF examination were normal. In the spinal cord, however, MRI showed diffuse cord swelling with signal change from C3 to T11 (fig 1). After three weeks the swelling had subsided and signal change was limited to T2 to T9. Six months later she continued to have a moderate paraparesis.

\section{PATIENT 10}

A 36 year old patient of African origin developed a non-specific gastroenteritis two weeks postpartum. Two weeks later there was a painful loss of vision in the left eye and concomitant complete transverse myelitis with bulbar and respiratory involvement necessitating mechanical ventilation. Six weeks later there was visual loss in the right eye. The CSF white cell count was 38 with a total protein of $208 \mathrm{mg} \%$. There was frank transudate of serum proteins with blood-brain barrier breakdown, but negative oligoclonal bands. Brain MRI (fig 2) showed 63 deep white matter lesions decreasing to 35 four months later. Spinal cord imaging showed diffuse swelling from the medulla to C7 and T3 to T5 (fig 3) which was less pronounced on follow up. Her clinical and MRI findings are consistent with probable acute disseminated encephalomyelitis. There was a slight response to intravenous steroids; she continues to have a moderate paraparesis and has reduced bilateral vision to counting fingers.

\section{PATIENT 11}

A 14 year old girl of Mediterranean origin developed bilateral consecutive visual loss to counting fingers over a four week period. 
Figure 3 Sagittal T2 weighted MRI with axial slice through C4 of patient 10 showing extensive swelling from the medulla to C7 with involvement of the whole diameter of the cord.
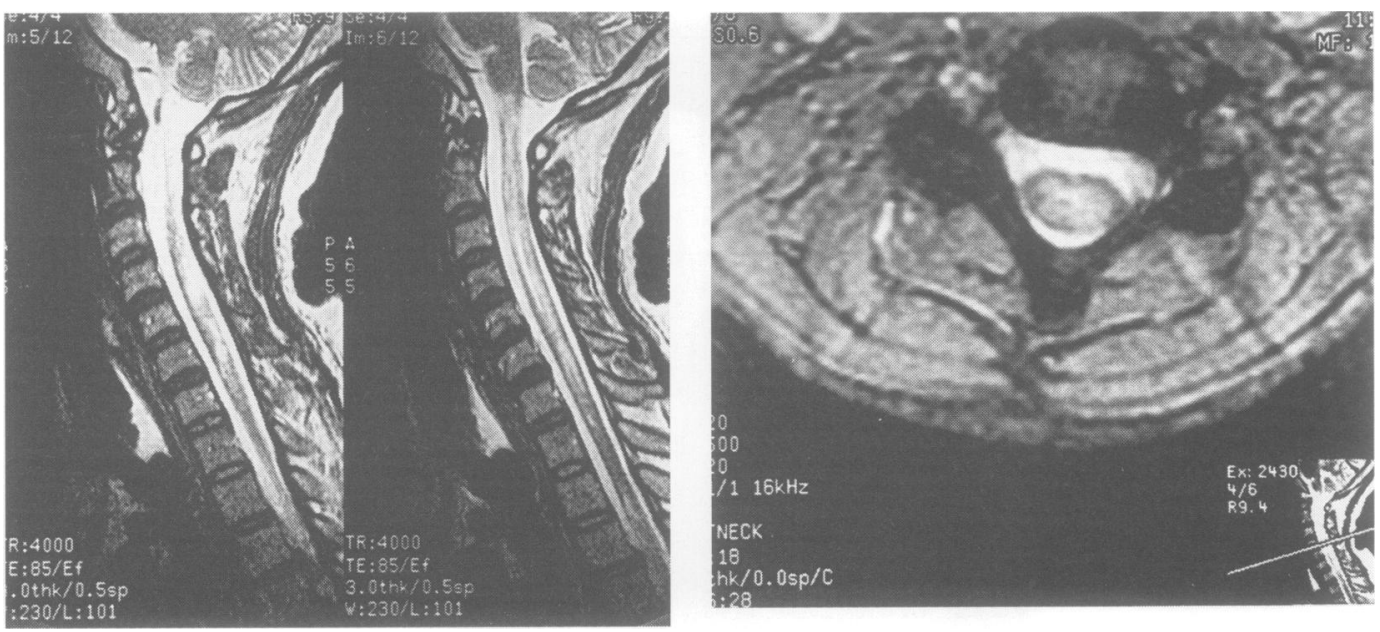

There was full recovery after intravenous steroids. Eighteen months later there was a recurrence with bilateral progressive visual failure unresponsive to steroids. Brain parenchyma MRI was normal; there was intrinsic enhancement of the optic nerve with swelling at the chiasm. Biopsy showed a reactive astrocytosis. Six months later she developed a complete transverse myelitis with a sensory level to T6. Brain MRI was again normal; MRI of the spinal cord showed diffuse swelling and signal change from $\mathrm{C} 3$ to $\mathrm{T} 5$. Her CSF showed a pleocytosis (white cell count $225 / \mathrm{mm}^{3} ; 80 \%$ polymorphs) and a protein count of $1.47 \mathrm{~g} / \mathrm{l}$. Oligoclonal bands were negative. She was unresponsive to steroids and remains paraparetic and blind.

\section{Discussion}

Since Devic's original description in 1894 of neuromyelitis optica there has been much debate regarding its aetiology. ${ }^{2-8}$ Without doubt, a specific cause or associated disease has been identified in a minority of cases, ${ }^{9-16}$ but in most it has not and in such patients the question has arisen whether or not Devic's neuromyelitis optica is a variant of multiple sclerosis. ${ }^{6-8}$ 17-19 Postmortem data in such cases has been inconclusive-in some there have reports of typical demyelinating lesions beyond the spinal cord and optic nerves as seen in classic multiple sclerosis, ${ }^{7}$ whereas other reports describe more destructive features such as necrosis and cavitation within the spinal cord along with thickening of vessel walls, ${ }^{820}$ features which are not expected in multiple sclerosis.

A difficulty in interpreting these and other published studies is the variable definition of the clinical criteria used to diagnose Devic's neuromyelitis optica. Involvement of the spinal cord and optic nerves without further qualification is insufficient-clearly many patients with multiple sclerosis would be included. Conversely, restricting inclusion only to those with a monophasic, simultaneous and severe affliction of the spinal cord and both optic nerves would exclude patients who seem to have a clinical pattern distinct from "classic" multiple sclerosis. Our classification is a compromise between these two extremes, which seems to us to best describe a group who present a real challenge in terms of diagnosis and management. The essential requirements were: (1) a severe (more or less complete) transverse myelitis, an uncommon finding in multiple sclerosis; (2) an acute unilateral or bilateral optic neuropathy; (3) no clinical involvement beyond the spinal cord or optic nerves, and (4) the illness could be monophasic or multiphasic. We were particularly interested in evaluating the CSF and MRI findings for brain and spinal cord in this group of patients.

In five of our 12 patients a probable aetiology was identified. Two had probable acute disseminated encephalomyelitis, with a monophasic bilateral optic neuritis and transverse myelitis developing within two weeks of a non-specific infectious illness. Brain MRI showed multifocal lesions of the cerebral white matter at presentation, some of which had resolved at follow up after four and 18 months without any new lesions developing, and spinal MRI showed swelling and signal change extending over many segments of the cord in the acute phase. These imaging features are all characteristic of acute disseminated encephalomyelitis and are atypical of multiple sclerosis in which new lesions often appear at follow up and spinal lesions are usually small. ${ }^{21-25}$

One patient had systemic lupus erythematosus, another mixed connective tissue disease, and a third had a history of pulmonary tuberculosis. The association of Devic's neuromyelitis optica with acute disseminated encephalomyelitis, systemic lupus erythematosus, and pulmonary tuberculosis has been previously noted. ${ }^{10-16}$ One patient with systemic lupus erythematosus had postmortem evidence of haemorrhage, vasculitis, extensive necrosis, and arachnoidal fibrosis in the spinal cord and optic nerves. ${ }^{10}$ The association of pulmonary tuberculosis and necrotic myelitis has also been reported by Hughes et al, who suggested that the pathogenesis may be an immune response of the spinal cord and optic nerves to the mycobacterial infection whether via a shared antigen, non-specific adjuvant effect, or other mechanisms. ${ }^{15}$ An immune mediated response seems more likely in our 
patients, and others described in the medical literature in whom the primary tuberculous infection had been successfully treated at the time of presentation with Devic's neuromyelitis optica. An immunopathogenic mechanism also seems highly likely in our patients with systemic lupus erythematosus, mixed connective tissue disease, and acute disseminated encephalomyelitis, given that these are accepted immune mediated conditions. Six other patients in our series exhibited a variety of organ specific autoantibodies which again points to an immunological mechanism for Devic's neuromyelitis optica.

Whereas we accept in certain instances that Devic's neuromyelitis optica may occur as a result of demyelination from multiple sclerosis, there are some clinical, CSF, and MRI features in our patients which would be unexpected in multiple sclerosis. Firstly, in the United Kingdom, multiple sclerosis is predominantly seen in the Caucasoid ethnic group; in the present series, only five of 12 were Caucasoid. ${ }^{26}$ Secondly, patients were often left with permanent and severe deficits after the acute episode, such an outcome being unusual in the early relapsing and remitting phase of multiple sclerosis. ${ }^{28}$ Thirdly, CSF oligoclonal bands and brain MRI white matter lesions were seen in only two of 12 and five of 11 of our patients respectively-in clinically definite multiple sclerosis such abnormalities are seen in over $90 \%$ of patients. ${ }^{29-31}$ Furthermore, follow up MRI showed partial resolution and/or no new lesions, an unlikely pattern for multiple sclerosis. Fourthly, the acute spinal cord lesion was invariably extensive, with swelling and signal change extending over many spinal cord segments. Although swelling is often seen in acute cord lesions due to multiple sclerosis, it is rare for the lesion to extend beyond a single segment. ${ }^{23}$

There have been some other recent reports of CSF and MRI findings in Devic's neuromyelitis optica. ${ }^{8323}$ The series of Mandler $e t$ al has several similarities to ours. ${ }^{8}$ Eight patients were described, none of whom had oligoclonal bands; brain MRI was normal in three patients studied with this modality. Fazekas et al describe two patients in whom there was swelling and enhancement in the chiasm during the acute illness (similar to our patient 11), but who had a normal brain MRI and no CSF oligoclonal bands. ${ }^{33}$

In conclusion, we believe that the present series of cases identifies Devic's neuromyelitis optica as a distinct nosological entity. Although it may have multiple specific causes, an immunopathogenic mechanism seems likely in all patients, and the clinical, MRI, and CSF features are distinct from those seen in relapsing-remitting multiple sclerosis.

1 Allbutt TC. On the ophthalmoscopic signs of spinal disease. Lancet $1870 ; \mathbf{i}: 76-8$.
2 Devic E. Myelite subaigue compliquee de nevrite optique. Bull Med 1894;8:1033-4.

3 Devic E. Myelite aigue dorse-lombaire avec nevrite optique, autopsie. Congress Francais Medicine (Premiere optique, autopsie. Congress
Session, Lyon) 1895;1:434-9.

4 Gault F. De la neuromyelite optique aigue. Lyon: Thesis 1894 5 Goulden C. Optic neuritis and myelitis. Ophthalmic Review 1914;34:193-209.

6 Beck GM. A case of diffuse myelitis associated with optic neuritis. Brain 1927;50:687-703

7 Stansbury FC. Neuromyelitis optica (Devic's disease) Presentation of five cases with pathological study and review of the literature. Arch ophthalmol 1949;42 292-335;465-501.

8 Mandler RN, Davis LE, Jeffery DR, Kornfeld MK. Devic's neuromyelitis optica: a clinicopathological study of 8 patients. Ann Neurol 1993;34:162-8.

9 Motumara S, Tabira T, Kuroiwa Y. A clinical comparative study of multiple sclerosis and neuro-Behcet's syndrome. f Neurol Neurosurg Psychiatry 1980;43:210-3.

10 April RS, Vansonnenberg E. A case of neuromyelitis optica (Devic's syndrome) in systemic lupus erythematosus: clinicopathological report and review of the literature. clinicopathological report and

11 Kinney EL, Beroff RL, Rao NS, Lay MF. Devic's syndrome and systemic lupus erythematosus. A case repor and review of the literature. Arch Neurol 1979;36:643-4.

2 Tola MR, Granieri E, Caniatti L, et al. Systemic lupus erythematosus presenting with neurological disorders. $\mathcal{F}$ Neurol 1992;239:61-4.

13 Goldman M, Herode A, Borenstein S, Zanen A. Optic neuritis, transverse myelitis and anti-DNA antibodies nine years after thymectomy for myasthenia gravis. Arth Rheum 1984;27:701-3.

14 Al-Deeb SM, Yaqub BA, Kjoja WO. Devic's neuromyelitis optica and varicella. $\mathcal{F}$ Neurol $1993 ; 240: 450-1$.

15 Hughes RAC, Mair WGP. Acute necrotic myelopathy with pulmonary tuberculosis. Brain 1973;100:223-38.

16 Silber MH, Willcox PA, Lowen RM, Unger A Neuromyelitis optica (Devic's syndrome) and pulmonary tuberculosis. Neurology 1990;40:934-8.

17 Mathews WB. In: Mathews WB, ed. McAlpine's multiple sclerosis. Edinburgh: Churchill Livingstone,171-2.

18 Fukazawa T, Hamada T, Tashiro $\mathrm{K}$, et al. Acute transverse myelitis in multiple sclerosis. F Neurol Sci 1990;100 217-22.

19 Ortiz de Zarate JC, Tamaroff L, Sica REP, Rodriguez JA. Neuromyelitis optica versus subacute necrotic myelitis: part II.Anatomical study of two cases. $\mathcal{F}$ Neurol Neuorsurg Psychiatry 1968;31:641-5.

20 Leonardi A, Arata L, Farinelli M, et al. Cerebrospinal fluid and neuropathological study in Devic's syndrome. and neuropathological study in Devic's syndrome. 1987;82:281-90.

21 Francis DA, Brown A, Miller DH, Wiles CM, Bennett ED, Leigh N. MRI appearances of the CNS manifestations of Mycoplasma pneumonia: a report of two cases. $\mathcal{f}$ Neurol 1988;235:441-3.

22 Kesselring J, Miller DH, Robb SA, et al. Acute dessiminated encephalomyelitis: MRI findings and the distinction from multiple sclerosis. Brain 1990;113:291-302.

23 Kidd D, Thorpe JW, Thompson AJ, et al. Spinal cord MRI using multi-array coils and fast spin echo. II. Findings in multiple sclerosis. Neurology 1993;43:2632-7.

24 Willoughby EW, Grochowski E, Li DK, Oger J, Kastrukoff LF, Paty DW. Serial magnetic resonance scanning in multiple sclerosis: a second prospective study in relapsing patients. Ann Neurol 1989;25:43-9.

25 Campi A, Filippi M, Comi E, Martinelli V, Baratti C, Rovaris M, Scotti G. Acute transverse myelopathy: spinal Rovaris $\mathrm{M}$, Scotti $\mathrm{G}$. Acute transverse myelopathy: spinal
and cranial $\mathrm{MR}$ study with clinical follow up. $A \mathcal{F N R} A m \mathcal{F}$ and cranial MR study with clinic

26 Compston DAS. Risk factors for multiple sclerosis: race or place? F Neurol Neurosurg Psychiatry 1990;53:821-3.

27 Swingler RJ, Compston DAS. The distribution of multiple sclerosis in the United Kingdom. $\mathcal{f}$ Neurol Neurosurg Psychiatry 1986;49:1115-24.

28 Trojano M, Avolio C, Manzari C, Calo A, De Robertis F, Serio G, Livrea P. Multivariate analysis of predictive factors of multiple sclerosis course with a validated method to assess clinical events. I Neurol Neurosurg Psychiatry 1995; 58:300-6.

29 Paty DW, Oger JJF, Kastrukoff LF, et al. MRI in the diagnosis of multiple sclerosis: prospective comparison of clinical evaluation, EPs, oligoclonal banding and CT. Neurology 1988;38:180-5.

30 Thompson AJ, Kermode AG, McManus DG, et al. Patterns of disease activity in multiple sclerosis: clinical and magnetic resonance imaging study. $B M F 1990 ; 300$ 631-4

31 Miller DH, McDonald WI, Blumhardt LD, et al. Magnetic resonance imaging in isolated non-compressive spinal cord syndromes. Ann Neurol 1987;22:714-23.

32 Tashiro K, Ito K, Mauro Y, et al. MR imaging of spinal cord in Devic's disease. $\mathcal{F}$ Comput Assist Tomogr 1987;11: 516-7.

33 Fazekas F, Offenbacher H, Strasser-Fuchs S. MRI of neuromyelitis optica: evidence for a distinct entity. $\mathcal{F}$ Neurol Neurosurg Psychiatry 1994;59:1140-2. 